\title{
CUTTINg Edge Microgeometry AND PREPARATION METHODS
}

\author{
Tomáš Vopát, Marcel Kuruc, Vladimír Šimna, Rudolf Zaujec, Jozef Peterka
}
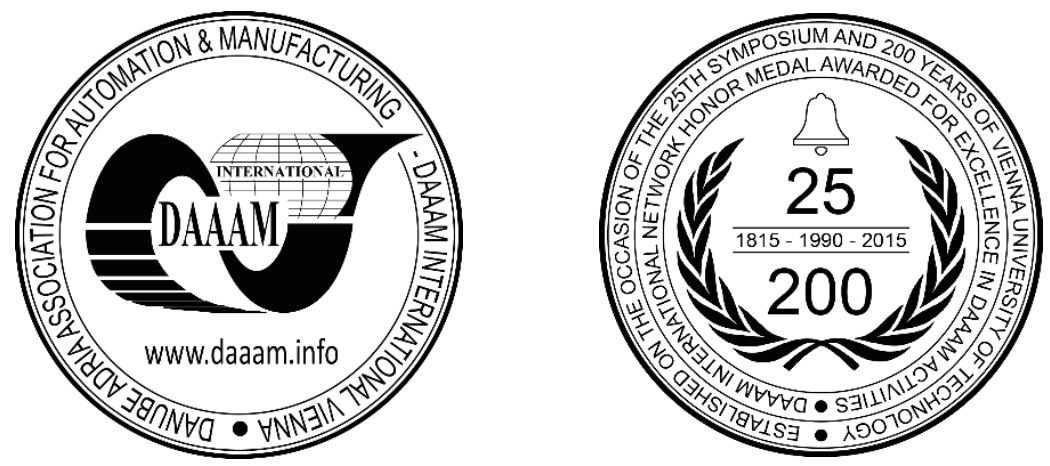

This Publication has to be referred as: Vopat, T[omas]; Kuruc, M[arcel]; Simna, V[ladimir]; Zaujec, R[udolf] \& Peterka, J[ozef] (2017). Cutting Edge Microgeometry and Preparation Methods, Proceedings of the 28th DAAAM International Symposium, pp.0384-0391, B. Katalinic (Ed.), Published by DAAAM International, ISBN 978-3-90273411-2, ISSN 1726-9679, Vienna, Austria

DOI: $10.2507 / 28$ th.daaam.proceedings.054

\begin{abstract}
The paper deals with the issue of cutting edge preparation and tool treatment before the coating and their influence on the tool life of coated cutting tools. The aim was to examine the influence of cutting edge radius sizes on the tool life of cemented carbide turning inserts. Theoretical analysis was focussed on the issue of cutting edge microgeometry, discussing the classification and importance of cutting edge microgeometry. The most famous and used edge preparation methods are summarized in article along with the results of current research of famous tool companies and institutions. In this article, the tool lives of cemented carbide turning inserts which were prepared by several methods were compared. Cemented carbide turning inserts were deposited by AlCrSiN nanocomposite hard coating. Long-term tool live tests were carried out on DMG CTX alpha 500 turning centre. The tool wear of cemented carbide turning inserts was measured on Dino-Lite digital microscope during the turning. The tool lives of prepared cemented carbide turning inserts with required cutting edge radius and unprepared ones were compared. These results were investigated in the process of machining of austenitic stainless steel material X6CrNiTi18-10 by DIN EN (AISI 321), which shows higher strain hardening tendency.
\end{abstract}

Keywords: Cutting Edge Preparation; Treatment; Cemented Carbide, Cutting Tool; Cutting Edge Microgeometry

\section{Introduction}

In the past years research in cutting tools field focused on optimum cutting edge microgeometry development of the cutting edge geometry and also on the preparation of the cutting tool surface for the coating process. The cutting edge geometry and the applied edge preparation methods affect the tool wear of coated cutting tools [1-3]. A thorough study of the efficiency of various cutting edge rounding methods as well as the effects of these treatments on the wear behaviour of coated tools in milling various metallic materials is introduced in [1].

In terms of edge characterization, it has thus far been expedient in most instances to specify the geometry of honed edges by a simple edge radius parameter. This inherently assumes the edge profile that bridges the rake and flank faces to conform to an arc of a circle. This need not however be the case, and indeed tool performance may be enhanced by rendering the cutting edge to be appropriately asymmetric [4]. Given the critical influence of edge geometric attributes on process responses, and the evolving capability of aforementioned novel processes in the generation of tailored cutting edges, it is imperative to develop methodologies for the comprehensive geometric characterization of the cutting edge. 
Publication [2] deals with the complexity of cutting edge microgeometry and evaluates its interactions with machining processes.

Publication [5] is concerned with the requirements and challenges in preparing and designing the cutting edge micro shape using wet abrasive jet machining. Wet abrasive jet machining with a robot guided system allows to prepare local tool areas and to realize a specific design of the cutting edge, as well as advantageous surface qualities.

Yussefian et al. [6] investigated sink electrical discharge machining as an optional method for controlled preparing of cutting edges by sinking the cutting edge into a counterface. Although the manufactured rounding variability is stated as minimal, the capability to prepare straight cutting edges is not limited by the tools' material hardness.

The application of laser machining for manufacturing the cutting edge roundness of cemented carbide inserts could have a beneficial effect on the wear behaviour of coated tools. The main advantage of using laser machining for manufacturing the cutting edge radii is the achievement of a reproducible micro-geometry [7, 8] as well as the capability of versatile application with respect to manufacturing of complex-shaped geometries and setting up high surface qualities for cemented carbide tools [9]. In [10], the feasibility of using laser machining for manufacturing the cutting edge roundness of cemented carbide inserts was investigated. In this context, diverse laser machining parameters such as of the laser-pulsing duration and -beam feed velocity were applied for shaping the cutting edge roundness. Hereupon, shorter laser pulsing durations in the order of pico-seconds and larger feed velocities eliminate the negative effects of a thermal affected zones associated with its thickness, material properties and adhesion on the coated tool life. Moreover, the conduct of micro-blasting on the already laser-treated cemented carbide substrates increases the effective coating adhesion, thus leading to a cutting performance improvement of the coated tools.

Experimental study on the surface roughness of tungsten alloy in Abrasive water jet cutting and laser cutting is discussed in $[11,12]$. In $[13,14]$ authors investigated influence of the cutting edge preparation on tool life of cemented carbide inserts when milling. Publication [15] deals with testing cemented carbide cutting tools with different cutting edge qualities obtained by different grinding conditions during the experimental cutting of Inconel 718 super-alloy.

The role of the meso-geometry of the cutting edge on the mechanics of chip formation was first documented by Albrecht [16] in 1960. It has however taken several decades since, for this important aspect to be accorded its due consideration. As the meso-geometry of a tool edge profile comprises two tool faces that flank the cutting edge (Fig. 1.), unambiguous identification of the transition points that separate the edge from the tool faces is the first step that should precede edge characterization [17].

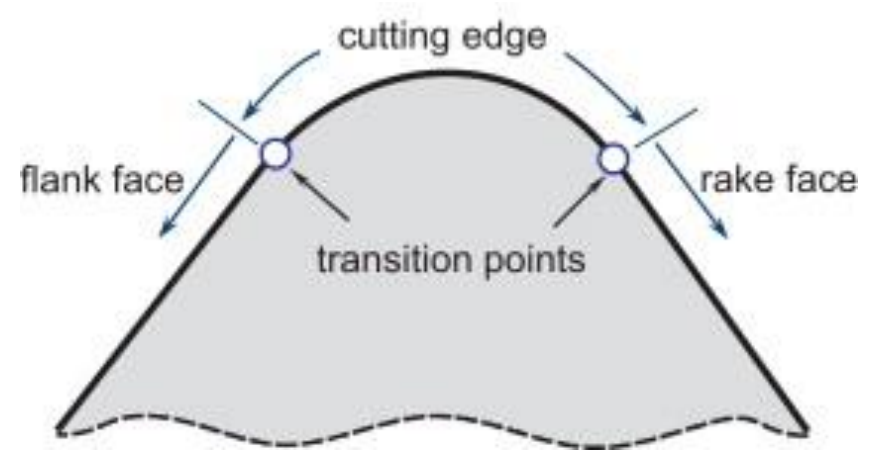

Fig. 1. Terminology of tool edge profile [17]

In terms of edge characterization, it has thus far been expedient in most instances to specify the geometry of honed edges by a simple edge radius parameter. This inherently assumes the edge profile that bridges the rake and flank faces to conform to an arc of a circle. This need not however be the case, and indeed tool performance may be enhanced by rendering the cutting edge to be appropriately asymmetric [4]. Given the critical influence of edge geometric attributes on process responses, and the evolving capability of aforementioned novel processes in the generation of tailored cutting edges, it is imperative to develop methodologies for the comprehensive geometric characterization of the cutting edge.

Denkena et al. [4] proposed that the edge geometry be characterized with reference to the virtual tool tip derived from the linear extension of flank and rake faces (Fig. 2). Any asymmetry in the edge geometry is signified by the ratio of distances $S_{\alpha}$ and $S_{\gamma}$ from the tool tip to points 1 and 2, from where the edge profile diverges away from the flank and rake faces, respectively. The degree of edge flattening is specified by parameter $\Delta r$ which is the distance from the virtual tool tip to the apex of the edge profile, and parameter $\varphi$ locates the tool apex relative to the tool faces. Such a characterization is simple and facilitates easy visualization of the edge; however, the said parameters are evaluated based on just three points on the edge profile, which are not adequate to uniquely characterize the edge geometry. Furthermore, publication [4] did not specify a method to objectively determine the transition points 1 and 2 wherefrom the edge profile deviates off the tool faces.

Rodriguez [18] and Wyen et al. attempted to address the issue above by defining the different approaches as Denkena et al. described. Wyen et al. $[19,20]$ recently proposed a method for identifying the transition points that delineate the meso-geometry of the cutting edge from the flank and rake faces of the tool. 


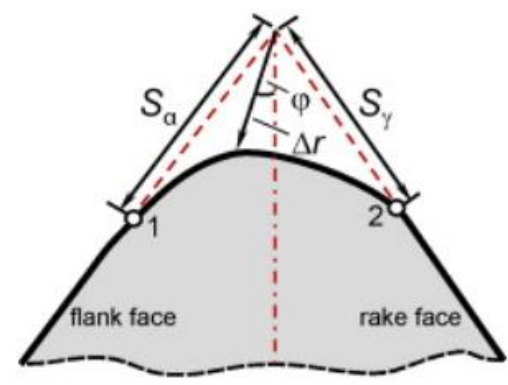

Fig. 2. Edge characterization methods due to Denkena et al. [4]

In publication [21], Denkena et al. presents a novel method for preparing of customized cutting edges by means of grinding. The reliability of the new method has been proven and the dependency of the obtained relative error on the chamfer size discussed. Moreover, an evaluation of the edge chipping has been carried out. It has been shown that preparing the edge as proposed by the method reduces the edge chipping by approximately $1 \mu \mathrm{m}$ in comparison to a sharp edge. Varying the micro geometry does not lead to a variation of the edge chipping. Influence of used edge preparation method on the coating adhesion to substrate is discussed in [22].

\section{Cutting edge preparation}

Article deals with the issue of cutting edge preparation and tool treatment prior to coating and their influence on the tool life as mentioned before. It is a well-known fact that cutting tool wear is a function of basic process parameters (Fig. 3). The publications in introduction presented that cutting the edge microgeometry has a great influence on the tool life. Blue boxes in Fig. 3 show the factors that were tested and changed in the article.

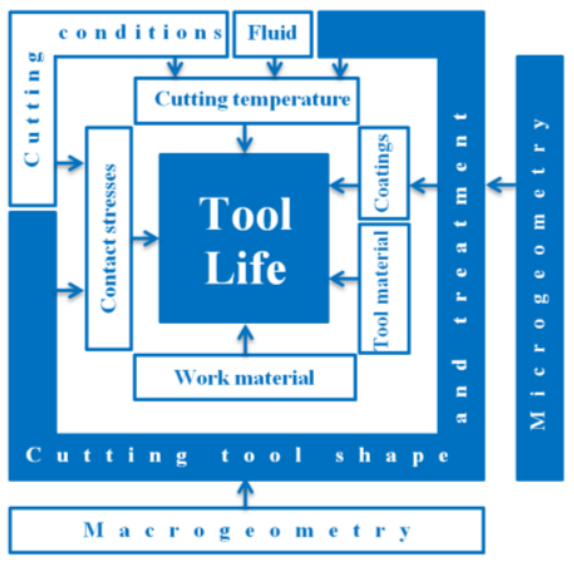

Fig. 3. Factors that were tested and changed

The aim of the article was to investigate influence of cutting edge radius $r_{n}$ sizes on the tool life in turning of austenitic stainless steel material where authors expected the great importance for this material group. The other aim was to compare the various edge preparation methods in term of tool life of cemented carbide turning inserts. With support of the Pramet Tools, s.r.o. Company, two industrially usual edge preparation methods were selected in this article:

- brushing is a method uses a rotary brushing with $\mathrm{SiC}$ grains

- wet microblasting with $\mathrm{Al}_{2} \mathrm{O}_{3}$ medium

Furthermore, cemented carbide turning inserts were manufactured with the three cutting edge radius sizes: $r_{n}=20 \mu \mathrm{m}$, $r_{n}=40 \mu \mathrm{m}, r_{n}=60 \mu \mathrm{m}$. The fourth cemented carbide turning insert was manufactured with $r_{n}=7.49 \mu \mathrm{m}$, where dry microblasting was only used for deburring but cutting edges were not further prepared. Then, cemented carbide turning inserts were cleaned in Elmasonic P ultrasonic unit. After cleaning, all cemented carbide turning inserts were deposited by $\mathrm{AlCrSiN}$ nanocomposite hard coating when deposition conditions were constant. Since, the coating thickness was 4 $\mu \mathrm{m}$, coated cemented carbide turning inserts were tested with the following cutting edge radius sizes in tool life test:

- $r_{n}=11.49 \mu \mathrm{m}$

- $r_{n}=24 \mu \mathrm{m}$

- $r_{n}=44 \mu \mathrm{m}$

- $r_{n}=64 \mu \mathrm{m}$ 
Zeiss LSM 700 laser confocal microscope and Accretech Surfcom measurement device were used to measure the cutting edge radius sizes.

\section{Materials and methods}

\subsection{Tested cutting tools and workpiece material}

The CNMG 120408E-SM turning inserts and PCLNL 2020K12 toolholder were selected for this research. Tested cutting tool material was cemented carbide. Specific grade of cemented carbide is HF10 by tool producer equivalent to K20 - K30 by ISO ( $89.6 \%$ of WC, $10 \%$ of Co and $0.4 \%$ of other carbides). The tool holder was cut due to reduce the effects of tool overhang on tool wear. There was selected very universal grade of cemented carbide with respect to semifinishing strategy, PVD coating and testing of various workpiece materials.

The selected workpiece material was austenitic stainless steel material of DIN EN X6CrNiTi18-10 (AISI 321) grade in this paper. Chemical composition is shown in Table 1 . We suggested a round bar with dimensions of $\varnothing 100 \times 150 \mathrm{~mm}$.

\begin{tabular}{|c|c|c|c|c|c|c|c|c|c|c|}
\hline Element & $\mathbf{C}$ & $\mathbf{S i}$ & $\mathbf{M n}$ & $\mathbf{P}$ & $\mathbf{S}$ & $\mathbf{C u}$ & $\mathbf{C r}$ & $\mathbf{N i}$ & $\mathbf{M o}$ & Ti \\
\hline wt. \% & 0.064 & 0.83 & 1.44 & 0.026 & 0.025 & 0.66 & 17.5 & 9.89 & 0.46 & 0.47 \\
\hline
\end{tabular}

Table 1. Chemical composition of machined material X6CrNiTi18-10

\subsection{Tool life test and cutting parameters}

For long-term tool life tests, DMG CTX alpha 500 turning centre was used. Turning without live centre support has to conform to the slenderness ratio $\mathrm{L} / \mathrm{D} \leq 4.5[23]$.

In cooperation with Pramet Tools Company, the feed and depth of cut were obtained from their research, which was oriented on chip forming of austenitic stainless steel material. For a long-term tool life test, cutting speed was investigated experimentally.

For studied coated cemented carbide turning inserts, the investigation of cutting speed corresponding to a tool life of 15 min was performed. Since, studied cemented carbide turning inserts had a several edge preparation methods, several cutting edge radii and modified own coating, there was necessary to determinate optimum cutting speed. This experiment was aimed at determining the cutting speed for the target function: tool life of $15 \mathrm{~min}$. For this experimental investigation, the coated cemented carbide turning inserts with cutting edge radius $r_{n}=40 \mu \mathrm{m}$ (as average value) were selected. The inserts were prepared by brushing.

On the basis of chip forming tests and long-term tool life tests, the cutting parameters (cutting speed, feed rate and depth of cut) of AlCrSiN coated cemented carbide turning inserts were established for turning austenitic stainless steel material and they are shown in Table 2. Experimental investigation of cutting parameters for this research in detail is published in [22].

\begin{tabular}{|c|c|c|}
\hline cutting speed $v_{\boldsymbol{c}}(\mathbf{m} / \mathbf{m i n})$ & feed $\boldsymbol{f}(\mathbf{m m})$ & depth of cut $\boldsymbol{a}_{\boldsymbol{p}}(\mathbf{m m})$ \\
\hline 127 & 0.2 & 1 \\
\hline
\end{tabular}

Table 2. Recommended cutting parameters for coated cemented carbide turning inserts

Tool wear of coated cemented carbide turning insert was measured on Dino-Lite digital microscope. Alusol ABF 10 coolant was used in the machining process. Since the flank wear of cemented carbide turning inserts was dominant, it was measured every $0.1 \mathrm{~m}$ length of cut for the first tests. After obtaining the flank wear behaviour, we measured width of flank wear after particular period of time considering evolution of flank wear. The machining tests were stopped when width of the flank wear reached over $0.25 \mathrm{~mm}$ because too large notch and edge chipping were observed over this value. Every type of cemented carbide turning insert was tested three times in order to exclude the impact of other factors involved in the process. After that, the average value was calculated.

\section{Results and discussion}

The graphs in Figs. 4 and 5 were plotted based on the width of flank wear value of particular measurement expresses the time dependence of width of flank wear. The time dependence of width of flank wear for prepared cemented carbides turning inserts with required cutting edge radii $r_{n}=24,44,64 \mu \mathrm{m}$ and for unprepared cemented carbide turning inserts with cutting edge radii $r_{n}=11.49 \mu \mathrm{m}$ were then compared.

For unprepared turning carbide inserts with $r_{n}=11.49 \mu \mathrm{m}$, the width of flank wear value reached over $0.25 \mathrm{~mm}$ after $26.1 \mathrm{~min}$ of cutting. For cemented carbide turning inserts prepared by specific edge preparation methods, the tool life was determined from the previous graphs (Fig. 4. and 5.) and inserted to Table 3. 


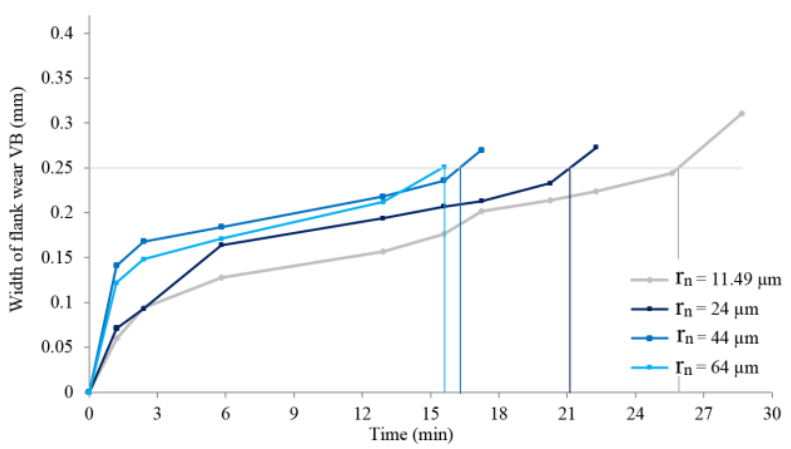

Fig. 4. Graph of time dependence of width of flank wear value VB (brushing)

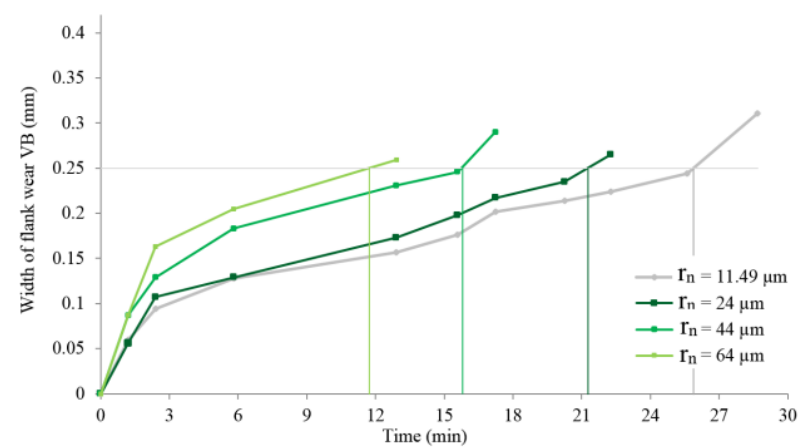

Fig. 5. Graph of time dependence of width of flank wear value VB (wet microblasting)

\begin{tabular}{|c|c|c|c|}
\hline & \multicolumn{3}{|c|}{ Tool life (min) } \\
\cline { 2 - 4 } & $\boldsymbol{r}_{\boldsymbol{n}} \mathbf{\mathbf { 2 4 }} \boldsymbol{\mathbf { \mu m }}$ & $\boldsymbol{r}_{\boldsymbol{n}}=\mathbf{4 4} \boldsymbol{\mu \mathbf { m }}$ & $\boldsymbol{r}_{\boldsymbol{n}}=\mathbf{6 4} \boldsymbol{\mu \mathbf { m }}$ \\
\hline Brushing & 21.3 & 16.4 & 15.5 \\
\hline Wet microblasting & 21.4 & 15.8 & 11.7 \\
\hline
\end{tabular}

Table 3. The tool life of cemented carbide turning inserts prepared by brushing and wet microblasting

Fig. 6 records just some example of the flank wear evolution of unprepared cemented carbide turning insert during the turning. Observed were too large edge chipping and notch just over $0.25 \mathrm{~mm}$ of width of flank wear. Micrographs are magnified 230 times.
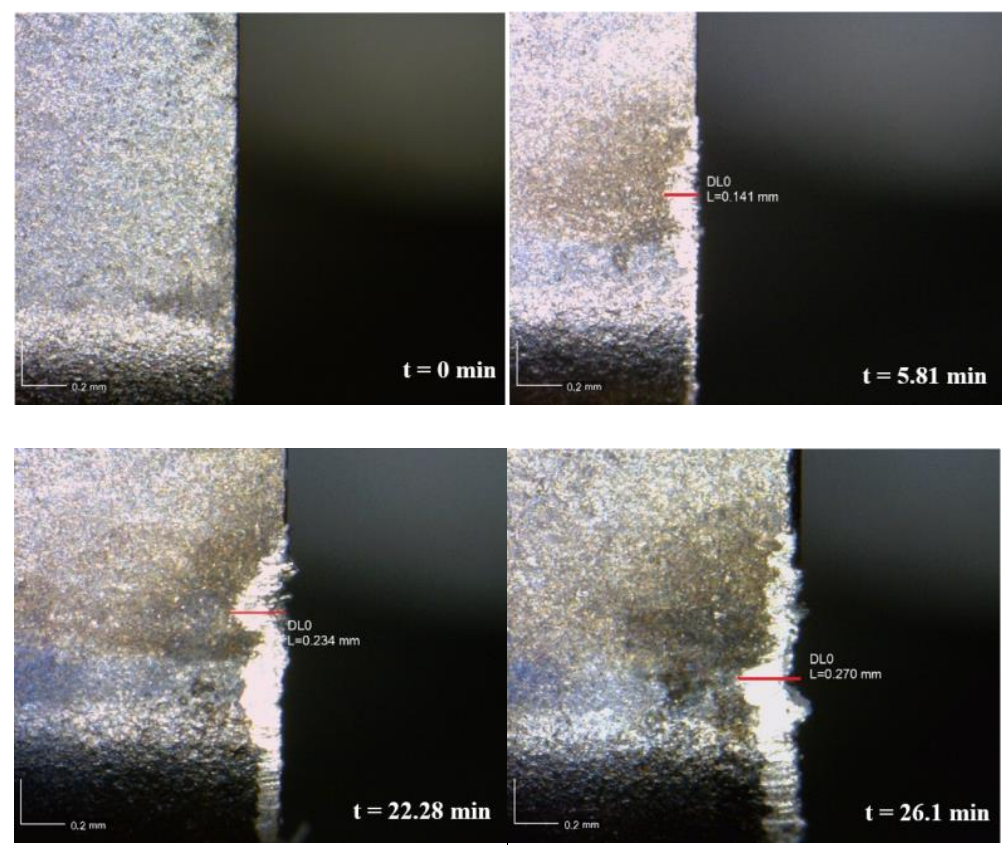

Fig. 6. Evolution of flank wear 
Micrographs of flank wear for cemented carbide turning inserts prepared by brushing are shown in Fig. 7 in the first line and the second line records flank wear of cemented carbide turning inserts prepared by wet microblasting after attaining the value over $0.25 \mathrm{~mm}$.
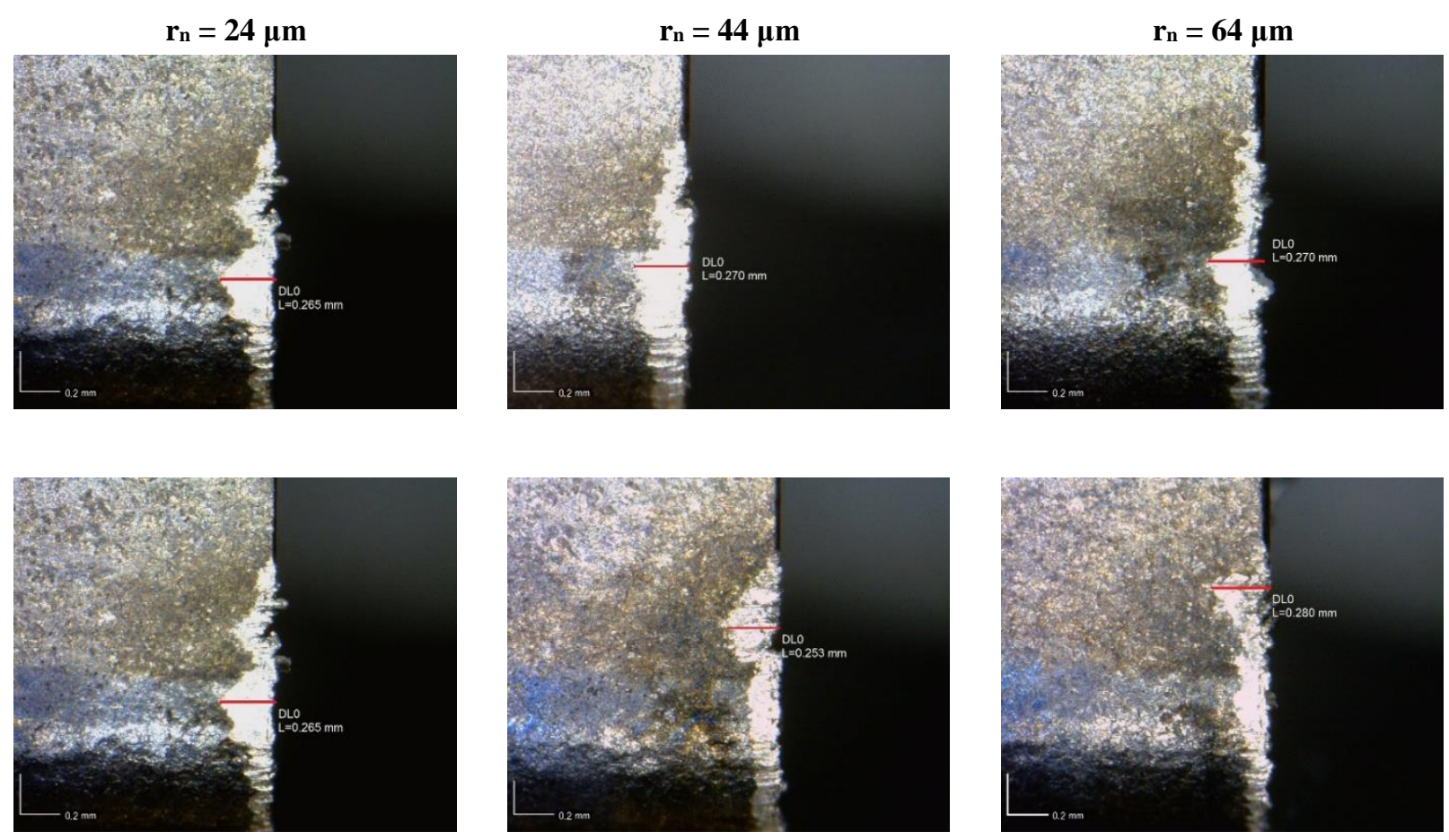

Fig. 7. Measured width of flank wear after attaining the value of $0.25 \mathrm{~mm}$

The results (Fig. 4 and 5) (Table 3) show that the tool life of cemented carbide turning inserts increases when cutting edge radius is smaller. The tool life of prepared cemented carbide turning inserts with cutting edge radius $r_{n}=44$ $\mu \mathrm{m}$ is approximately $18 \%$ longer than prepared cemented carbide turning inserts with cutting edge radius $r_{n}=64 \mu \mathrm{m}$. The tool life of prepared cemented carbide turning inserts with $r_{n}=24 \mu \mathrm{m}$ is approximately $32 \%$ longer than prepared cemented carbide turning inserts with $r_{n}=64 \mu \mathrm{m}$. In addition, the tool life of unprepared cemented carbide turning inserts with $r_{n}=11.49 \mu \mathrm{m}$ is approximately $22 \%$ longer than prepared cemented carbide turning inserts with $r_{n}=24 \mu \mathrm{m}$. These results were investigated in turning of austenitic stainless steel material, which shows higher strain hardening tendency.

Authors suppose that it is due to work hardening (also strain hardening) which is related to stagnation zone. Under stagnation (or separation) point (Fig. 8), workpiece material is pressed and therefore machined surface is significantly harder than work surface. Authors also suppose that bigger cutting edge radius made greater work hardening. Hence, if cutting edge radius is bigger than tool life will be shorter due to machining harder workpiece material.

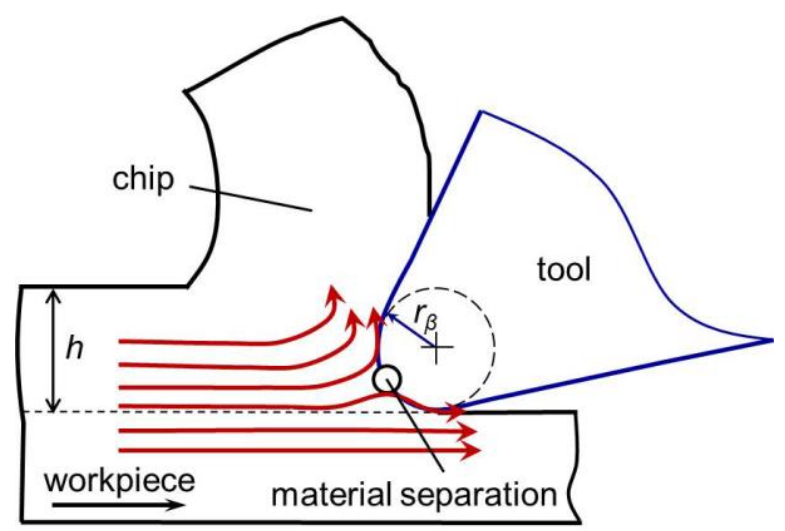

Fig. 8. Stagnation zone and stagnation (or separation) point [18]

The tool life of prepared cemented carbide turning inserts by brushing is approximately the same as tool life of prepared cemented carbide turning inserts by wet microblasting for cutting edge radii of 24 and $44 \mu \mathrm{m}$. The tool life of turning cemented carbide inserts prepared by brushing is approximately $32 \%$ longer than cemented carbide turning inserts prepared by wet microblasting for cutting edge radius $r_{n}=64 \mu \mathrm{m}$. 


\section{Conclusion}

This paper presents importance of cutting edge microgeometry. The most famous and used edge preparation methods are summarized in article along with the results of current research of famous tool companies and institutions. In this article, the influence of cutting edge radius sizes on the tool life was investigated. Furthermore, the various edge preparation methods were compared in term of tool life of turning inserts.

Solution to this issue consists of the following steps: measurement of unprepared turning carbide inserts, cutting edge preparation and surface treatment, measurement of prepared turning carbide inserts, cleaning, PVD coating, long-term tool life tests and evaluation. Tested cutting tool material was cemented carbide and selected workpiece material was austenitic stainless steel material of DIN EN X6CrNiTi18-10 (AISI 321) grade. Cemented carbide turning inserts were deposited by AlCrSiN nanocomposite hard coating. Tool lives of cemented carbide turning inserts were determined during the machining on DMG CTX alpha 500 turning centre. Since the flank wear of cemented carbide turning inserts was dominant, evolution of flank wear was measured during the test. The machining tests were stopped when width of the flank wear reached over $0.25 \mathrm{~mm}$ because too large notch and edge chipping were observed over this value.

The tool life of prepared cemented carbide turning inserts by brushing is approximately the same as tool life of prepared cemented carbide turning inserts by wet microblasting for cutting edge radii smaller than $45 \mu \mathrm{m}$. The tool life of turning cemented carbide inserts prepared by brushing is approximately $32 \%$ longer than cemented carbide turning inserts prepared by wet microblasting for cutting edge radius $r_{n}=64 \mu \mathrm{m}$.

The results show that the tool life of cemented carbide turning inserts increases when cutting edge radius is smaller. In addition, the tool life of unprepared cemented carbide turning inserts is longer than prepared ones. This phenomenon occurs during the machining of austenitic stainless steel material when cutting parameters as depth of cut and feed are selected for semi-finishing and finishing operations.

In the future research, an experiments for roughing, that means higher feed and larger depth of cut, will be completed. In general, these results can't be used for other material for sure. Thus, if we want to determine the influence of cutting edge radius sizes on the tool life in machining then it will be necessary to study other workpiece materials. Authors are going to focus on investigation of issue of cutting edge microgeometry during the machining the difficult-tomaterials material such as Inconel superalloy and hardened steel.

\section{Acknowledgments}

The article was written with the support of the Project of VEGA grant agency of the Ministry of Education, Science, Research and Sport of the Slovak Republic and Slovak Academy of Sciences, no. 1/0097/17: "The research of novel method for cutting edge preparation to increase the tool performance in machining of difficult-to-machine materials", and APVV Project of Slovak Research and development Agency of the Ministry of Education, Science, Research and Sport of the Slovak Republic, no. APVV-16-0057: "Research into the Unique Method for Treatment of Cutting Edge Microgeometry by Plasma Discharges in Electrolyte to Increase the Tool Life of Cutting Tools in Machining of Difficultto-Machine Materials."

This article was supported by PRAMET TOOLS and therefore I am grateful to R\&D department, which was involved in this research.

\section{References}

[1] Bouzakis, K.-D., Bouzakis, E., Kombogiannis, S., Makrimallakis, S., Skordaris, G., Michailidis, N., Charalampous, P., Paraskevopoulou, R., M'Saoubi, R., Aurich, J.C., Barthelmä, F., Biermann, D., Denkena, B., Dimitrov, D., Engin, S., Karpuschewski, B., Klocke, F., Özel, T., Poulachon, G., Rech, J., Schulze, V., Settineri, L., Srivastava, A., Wegener, K., Uhlmann, E., Zeman, P. (2014). Effect of Cutting Edge Preparation of Coated Tools on Their Performance in Milling Various Materials. CIRP Journal of Manufacturing Science and Technology, 7 (3), pp. 264273

[2] Denkena, B., Biermann, D. Cutting Edge Geometries. (2014). CIRP Annals - Manufacturing Technology, Volume 63, pp. 631-653

[3] Uhlmann, E., Oberschmidt, D., Löwenstein A., Kuche, Y. (2016). Influence of Cutting Edge Preparation on the Performance of Micro Milling Tools. Procedia CIRP. Volume 46, Pages 214-217

[4] Denkena, B., Lucas, A., Bassett. (2011). E. Effects of the cutting edge microgeometry on tool wear and its thermo mechanical load. CIRP Annals - Manufacturing Technology, Volume 60, pp. 73-76

[5] Biermann, D., Aßmuth, R., Schumann, S., Rieger, M., Kuhlenkötter, B. (2016). Wet Abrasive Jet Machining to Prepare and Design the Cutting Edge Micro Shape. Procedia CIRP, Volume 45, pp.195-198

[6] Yussefian, N.Z., Koshy, P., Buchholz, S., Klocke F. (2010). Electro-erosion Edge Honing of Cutting Tools. CIRP Annals, Volume 59 (1), pp. 215-218

[7] Breidenstein, B., Gey, C., Denkena, B. (2013). Surface Integrity of Laser Machined Carbide Cutting Tools Within the PVD-coating Process Chain Materialwissenschaft und Werkstofftechnik, Volume 44 (8), pp. 704-709

[8] Aurich, J.C., Zimmermann, M., Leitz, L. (2011). The Preparation of Cutting Edges Using a Marking Laser Production Engineering -Research and Development, Volume 5 (1), pp. 17-24 
[9] Uhlmann, E., Richarz, S., Mihotovic, V. (2009). Substrate Pre-treatment of Cemented Carbides using Abrasive Flow Machining and Laser Beam Ablation. Production Engineering, Volume 3 (1), pp. 81-86

[10] Bouzakis, K.-D., Charalampous, P., Kotsanis T., Skordaris, G., Bouzakis, E., Denkena, B., Breidenstein, B., Aurich, J.C., Zimmermann, M., Herrmann, T., M'Saoubi, R. (2017). Effect of HM substrates' cutting edge roundness manufactured by laser machining and micro-blasting on the coated tools' cutting performance. CIRP Journal of Manufacturing Science and Technology. Volume 18, pp. 188-197

[11] Begic-Hajdarevic, B., Cekic, A., Mehmedovic, M., Djelmic. A. (2015). Experimental Study on Surface Roughness in Abrasive Water Jet Cutting. Procedia Engineering, Volume 100, pp. 394-399

[12] Begic-Hajdarevic, D., Pasic, M., Cekic, A., Mehmedovic, M. (2016). Optimization of process parameters for cut quality in $\mathrm{CO} 2$ laser cutting using taguchi method. Annals of DAAAM and Proceedings of the International DAAAM Symposium. Volume 27, Issue 1, Pages 157-164

[13] Fulemová, J., Řehoř, J. (2015). Influence of form factor of the cutting edge on tool life during finishing milling. Procedia Engineering, Volume 100, pp. 682-688.

[14] Fulemova, J. Janda, Z. (2014). Influence of the cutting edge radius and the cutting edge preparation on tool life and cutting forces at inserts with wiper geometry. Procedia Eng., Volume 69, pp. 565-573.

[15] Baksa, T., Schornik, V., Adamek, P., Zetek, M. (2016). Machining of inconel 718 using uncoated cutting tools with different cutting EDGE quality. Annals of DAAAM and Proceedings of the International DAAAM Symposium, Volume 27, Issue 1, pp. 441-446.

[16] Albrecht P. (1960). New developments in the theory of metal cutting process. Part 1: The ploughing process in metal cutting. Journal of Engineering for Industry. Volume 82. pp. 348-57.

[17] Yussefian, N.Z., Koshy, P. (2013). Parametric characterization of the geometry of honed cutting edges. Precision Engineering. Volume 37, Issue 3, pp. 746-752.

[18] Rodriguez CJC. (2009). Cutting edge preparation of precision tools by applying microabrasive jet machining and brushing. Dissertation. Kassel University

[19] Wyen, C.-F., Knapp, W., Wegener. K. (2012). A new method for the characterisation of rounded cutting edges. International Journal of Advanced Manufacturing Technology, Volume 59, pp. 899-914

[20] Wyen, C.-F., Wegener, K. (2010). Influence of cutting edge radius on cutting forces in machining titanium. In: CIRP Annals - Manufacturing Technology. Vol. 59, pp. 93-96.

[21] Denkena, B. Kohler, J. Ventura, C.E.H. (2013). Customized cutting edge preparation by means of grinding. Volume 37, Issue 3, pp. 590-598.

[22] Vopát, T., Haršáni, M., Kuruc, M., Šimna, V., Zaujec, R., Peterka, J., Čaplovič, L. (2017). Effect of Substrate Bias and Coating Thickness on the Properties of nc-AlCrN/a-SixNy Hard Coating and Determination of Cutting Parameters. Solid State Phenomena. Volume 261, pp. 229-236.

[23] Vopát, T., Beňo, M. et al. (2014). Errors in turning slender workpieces. In EQ-2014: In the framework of International Forum "Education Quality - 2014". Proceedings. Izhevsk, Russia. pp. 256-260. 